\title{
Estimation of Liver Fat by FibroScan in Patients With Nonalcoholic Fatty Liver Disease
}

Rupesh Shrestha ${ }^{1}$, Sudhamshu KC ${ }^{1}$, Pukar Thapa ${ }^{1}$, Arbinda Pokharel ${ }^{1}$, Niyanta Karki ${ }^{1}$, Bikash Jaishi ${ }^{1}$

1. Liver Unit, Bir Hospital, National Academy of Medical Sciences, Kathmandu, NPL

Corresponding author: Rupesh Shrestha, merupeshth101@gmail.com

\section{Abstract}

\section{Background}

Assessment of nonalcoholic fatty liver disease (NAFLD) includes estimation of liver fat (steatosis). Controlled attenuation parameter (CAP) value obtained by FibroScan ${ }^{\circledR}$ (Echosens, Paris, France) is an alternative to liver biopsy for diagnosing and estimating steatosis (S). This study aimed to estimate the liver fat by CAP in NAFLD patients.

\section{Methods}

An observational cross-sectional study was conducted at the Liver Unit of Bir Hospital, from January 2021 to May 2021 after ethical clearance from the Institutional Review Board of the National Academy of Medical Sciences. A convenient sampling method was used. Data were analyzed with descriptive and inferential statistics involving bivariate and multivariate analysis.

\section{Results}

A total of 127 NAFLD patients were enrolled. The mean $( \pm$ SD) CAP value was $271.53( \pm 50.69) \mathrm{dB} / \mathrm{m}$. Total cholesterol, triglyceride, and body mass index (BMI) correlated positively $(\mathrm{p}<0.05)$ while systolic blood pressure correlated negatively with CAP value $(\mathrm{p}=0.031)$. On multivariate analysis, patients with $\mathrm{BMI} \geqslant 25$ $\mathrm{kg} / \mathrm{m}^{2}$ were found 3.7 times more likely to have $\mathrm{CAP} \geqslant 291 \mathrm{~dB} / \mathrm{m}$ (S3, severe steatosis) than those with BMI $<25 \mathrm{~kg} / \mathrm{m}^{2}(\mathrm{p}=0.048,95 \%$ CI $1.01,13.50)$. The mean $( \pm \mathrm{SD})$ CAP values were $276.19( \pm 49.93)$ and 246.60 $( \pm 48.50) \mathrm{dB} / \mathrm{m}$ among those with $\mathrm{BMI} \geqslant 25 \mathrm{~kg} / \mathrm{m}^{2}$ and $<25 \mathrm{~kg} / \mathrm{m}^{2}$, respectively $(\mathrm{p}=0.016$, using independent $\mathrm{t}-$ test). CAP steatosis grading correlated positively with both the ultrasound grading $(\mathrm{p}<0.001)$ and fibrosis grading by liver stiffness measurement $(\mathrm{p}=0.004)$.

\section{Conclusion}

In this observational cross-sectional study of NAFLD patients, the mean $( \pm \mathrm{SD})$ CAP value was $271.53( \pm 50.69)$ $\mathrm{dB} / \mathrm{m}$, which corresponds to moderate steatosis (S2). Obese NAFLD patients with $\geqslant 25 \mathrm{~kg} / \mathrm{m}^{2}$ were 3.7 times more likely to have severe steatosis (S3) than nonobese NAFLD patients with BMI $<25 \mathrm{~kg} / \mathrm{m}^{2}$.

Review began 06/20/2021 Review ended 07/07/2021 Published 07/15/2021

\section{○ Copyright 2021}

Shrestha et al. This is an open access article distributed under the terms of the Creative Commons Attribution License CC-BY 4.0., which permits unrestricted use, distribution, and reproduction in any medium, provided the original author and source are credited.
Categories: Internal Medicine, Gastroenterology

Keywords: body mass index, controlled attenuation parameter, fibroscan, liver fat, non-alcoholic fatty liver disease

\section{Introduction}

Nonalcoholic fatty liver disease (NAFLD) is the most common cause of fatty liver (steatosis). It represents infiltration of fat in the liver (more than $5-10 \%$ of hepatocytes) without excessive alcohol consumption and other causes of liver disease.

The assessment of NAFLD should also include estimation of liver fat. This helps anticipate future cardiometabolic risk, treatment monitoring, and liver graft assessment in live donor [1-3]. Liver biopsy (LB) is the gold standard for diagnosis and assessment of the severity of steatosis and grading of fibrosis. However, it is an invasive method, difficult to reproduce and usually, patients are not ready for this. Controlled attenuation parameter (CAP) value obtained by FibroScan ${ }^{\circledR}$ (Echosens, Paris, France) is an alternative method for diagnosing and estimating steatosis with good accuracy, lower cost, and without any complications.

This study aimed to estimate the liver fat by CAP in NAFLD patients and to find out the correlation between CAP values and ultrasound grading of steatosis and other co-variates.

\section{Materials And Methods}

This was an observational cross-sectional study conducted at the Liver Unit of Bir Hospital, a tertiary care 
center of Nepal, from January 2021 to May 2021 after ethical clearance from the Institutional Review Board of National Academy of Medical Sciences, Bir Hospital, Kathmandu (reference no. 529/2077/78).

All adults (aged $\geqslant 18$ years) with a diagnosis of NAFLD by ultrasonography (USG) were included in the study while patients with a history of significant alcohol intake (>20 g/day in females and $30 \mathrm{~g} /$ day in males), those using medications that can cause fatty liver, pregnant patients, those with acute or chronic viral hepatitis, and those not providing consent were excluded.

Patients were evaluated for the presence of metabolic syndrome (MetS) as per Modified National Cholesterol Education Program Adult Treatment Panel III 2005 criteria [4]. Waist circumference (WC) was measured at the midpoint between the lowest margin of the least palpable rib and the top of the iliac crest in the standing position. Individuals with BMI $\geqslant 25 \mathrm{~kg} / \mathrm{m}^{2}$ were considered obese. NAFLD patients who were not obese (BMI $<25 \mathrm{~kg} / \mathrm{m}^{2}$ in non-Asians, $<23 \mathrm{~kg} / \mathrm{m}^{2}$ in Asians) were defined as "lean NAFLD." Blood pressure, both systolic blood pressure (SBP), and diastolic blood pressure (DBP) were recorded in the supine position. Hypertension (HTN) was diagnosed when SBP was $\geqslant 130 \mathrm{mmHg}$ and/or DBP $\geqslant 85 \mathrm{mmHg}[4]$.

Blood samples were obtained and sent for investigations like fasting blood glucose (FBG), fasting lipid profile that included total cholesterol, triglycerides (TG), high-density lipoprotein (HDL) cholesterol and low-density lipoprotein (LDL) cholesterol, glycated hemoglobin (HbA1c), hemoglobin (Hb), and liver biochemistry that included total bilirubin (TB), direct bilirubin (DB), alanine aminotransferase (ALT), aspartate aminotransferase (AST), alkaline phosphatase (ALP), gamma-glutamyl transferase (GGT), prothrombin time (PT) and international normalized ratio (INR). Dyslipidemia was defined as elevation of total cholesterol $\geqslant 200 \mathrm{mg} / \mathrm{dL}, \mathrm{TG} \geqslant 150 \mathrm{mg} / \mathrm{dL}$, or both, or a low HDL cholesterol level ( $<50 \mathrm{mg} / \mathrm{dL}$ in females, $<40 \mathrm{mg} / \mathrm{dL}$ in males).

FibroScan ${ }^{\circledR}$ was used for the measurement of liver stiffness and CAP via transient elastography. The M probe was used in the first instance so that both liver stiffness measurement (LSM) and CAP could be obtained. The XL probe catering for obese patients was used when the M probe failed. At least 10 valid measurements were obtained in each patient. A success rate of $\geqslant 60 \%$ (number of validated measurements divided by the total number of measurements) and the ratio of the interquartile range (IQR) of liver stiffness to the median (IQR/MLSM) $\leqslant 30 \%$ were considered reliable and used for the final analysis [5].

Ultrasonography and FibroScan of each patient were performed by different hepatologists with experience of at least five years. Both operators were blinded by the results. CAP cut-off values indicating liver steatosis (S) were adapted from the study by Kamali et al. as follows: (1) $<237 \mathrm{~dB} / \mathrm{m}$ (S0, no steatosis), (2) 237.0-259.0 $\mathrm{dB} / \mathrm{m}$ (S1, mild steatosis), (3) 259.0-291.0 dB/m (S2, moderate steatosis), and (4) 291.0-400.0 dB/m (S3, severe steatosis) [6]. The cut-off values for fibrosis (F) were also adopted from the same study as follows: (1) $<5.5 \mathrm{kPa}$ (F0, no fibrosis), (2) 5.5-8.0 kPa (F1, mild fibrosis), (3) 8.0-10.0 kPa (F2, moderate fibrosis), (4) $11.0-16.0 \mathrm{kPa}$ (F3, severe fibrosis), and (5) $>16.0 \mathrm{kPa}$ (F4, cirrhosis) [6].

The data were entered in Microsoft Excel which was then cleaned and checked for any inconsistencies. The data were then coded and exported to SPSS for Windows version 16.0 (Chicago: SPSS Inc.) for analysis. Categorical data were described with frequency and percentage, while mean and standard deviation (SD) were calculated along with minimum and maximum values for presenting continuous data.

Inferential statistics involved bivariate and multivariate analysis. Correlation of the continuous independent variables with CAP values was assessed using Pearson correlation. Similarly, correlation of the steatosis grading by CAP with USG grading and fibrosis grading by LSM was done using Spearman rank correlation. Chi-square test was applied to see the association of CAP with different categorical independent variables, while independent t-test was used to compare the CAP values of different categories. Univariate logistic regression was applied to calculate the odds ratio (OR) and its $95 \% \mathrm{CI}$ for the independent variables. All the variables with $\mathrm{p}$-value $<0.25$ in univariate logistic regression were considered for collinearity test before taking for multivariate analysis. Those variables with variation inflation factor $(\mathrm{VIF}<2)$ in collinearity test were then taken into multivariate analysis. Multivariate logistic regression was applied to calculated adjusted odds ratio and the confidence interval.

\section{Results}

A total of 127 NAFLD patients were enrolled. While $84.3 \%$ of the patients were obese (BMI $\geqslant 25 \mathrm{~kg} / \mathrm{m}^{2}$ ), the mean ( \pm SD) BMI was $28.41( \pm 3.83) \mathrm{kg} / \mathrm{m}^{2}$. More than half of the patients had HTN $(51.2 \%)$ and MetS $(89.98 \%)$ (Table 1). 


\section{Cureus}

\begin{tabular}{|c|c|c|}
\hline \multicolumn{2}{|l|}{ Characteristics } & Frequency (Percentage)/N \\
\hline \multicolumn{2}{|l|}{ Sex (male:female) } & $86(67.7 \%): 41(32.3 \%)$ \\
\hline \multicolumn{2}{|l|}{ Age (years) } & $50.25 \pm 9.53(30,82)$ \\
\hline \multicolumn{2}{|l|}{ BMI $\left(\mathrm{kg} / \mathrm{m}^{2}\right)$} & $28.41 \pm 3.83(20.1,42.2)$ \\
\hline \multicolumn{2}{|l|}{$\mathrm{BMI} \geq 25\left(\mathrm{~kg} / \mathrm{m}^{2}\right)$} & $107(84.3 \%)$ \\
\hline \multirow{3}{*}{ Waist circumference $(\mathrm{cm})$} & Male & $101.28 \pm 4.46(82.5,108.5)$ \\
\hline & Female & $92.00 \pm 5.85(81.6,104.8)$ \\
\hline & Total & $98.29 \pm 6.58(81.6,108.5)$ \\
\hline \multicolumn{2}{|l|}{ Diabetes } & $44(34.6 \%)$ \\
\hline \multicolumn{2}{|l|}{ Hypertension } & $65(51.2 \%)$ \\
\hline \multicolumn{2}{|l|}{ Other chronic diseases } & 25 (19.7\%) \\
\hline \multicolumn{2}{|l|}{ Dyslipidemia } & $106(83.5 \%)$ \\
\hline \multicolumn{2}{|l|}{ Metabolic syndrome } & $113(88.98 \%$ \\
\hline
\end{tabular}

TABLE 1: Basic socio-demographic and clinical characteristics of patients $(n=127)$

BMI: body mass index, SD: standard deviation

Most of the patients had dyslipidemia (83.5\%) with mean ( \pm SD) total cholesterol, LDL cholesterol, HDL cholesterol, and TG being $222.25( \pm 50.67) \mathrm{mg} / \mathrm{dL}, 120.54( \pm 29.73) \mathrm{mg} / \mathrm{dL}, 43.3( \pm 10.29) \mathrm{mg} / \mathrm{dL}$, and 231.61 $( \pm 90.89) \mathrm{mg} / \mathrm{dL}$, respectively. Mean of TB, DB, AST, ALP was normal, but mean ( \pm SD) ALT was high, 57.72 $( \pm 36.08) \mathrm{IU} / \mathrm{L}$ (Table 2). 


\section{Cureus}

\begin{tabular}{ll}
\hline Characteristics & Mean \pm SD (Min, Max) \\
\hline Total cholesterol (mg/dL) & $222.25 \pm 50.67(113,346)$ \\
LDL cholesterol (mg/dL) & $120.54 \pm 29.73(40,212)$ \\
HDL cholesterol (mg/dL) & $43.3 \pm 10.29(21,82)$ \\
\hline TG (mg/dL) & $231.61 \pm 90.89(35,405)$ \\
FBG (mg/dL) & $123.13 \pm 50.81(78,452)$ \\
\hline HbA1c & $6.46 \pm 0.85(5,8.9)$ \\
\hline Hb (g/dL) & $14.25 \pm 1.63(10.2,18.5)$ \\
TB (mg/dL) & $0.94 \pm 0.59(0.2,4.1)$ \\
DB (mg/dL) & $0.25 \pm 0.18(0.01,1.2)$ \\
AST (IU/L) & $38.7 \pm 18.31(15,103)$ \\
ALT (IU/L) & $57.72 \pm 36.08(16,201)$ \\
ALP (IU/L) & $116.51 \pm 37.24(47,258)$ \\
GGT (IU/L) & $62.05 \pm 25.56(12,178)$ \\
PT (sec) & $13.16 \pm 1.39(10,17.7)$ \\
INR & $1.05 \pm 0.16(0.8,1.51)$
\end{tabular}

\section{TABLE 2: Biochemical parameters of the patients $(n=127)$}

LDL: low-density lipoprotein, HDL: high-density lipoprotein, TG: triglyceride, FBG: fasting blood glucose, HbA1c: glycated hemoglobin, Hb: hemoglobin, TB: total bilirubin, DB: direct bilirubin, AST: aspartate aminotransferase, ALT: alanine aminotransferase, ALP: alkaline phosphatase, GGT: gamma-glutamyl transferase, PT: prothrombin time, INR: international normalized ratio, SD: standard deviation

The mean ( ${ }^{ \pm} \mathrm{SD}$ ) CAP was $271.53( \pm 50.69) \mathrm{dB} / \mathrm{m}$, but about $20.5 \%$ of the patient diagnosed to have NAFLD by USG had no steatosis (SO) during CAP evaluation by FibroScan (Table 3). The mean ( \pm SD) CAP among lean NAFLD (BMI $<23 \mathrm{~kg} / \mathrm{m}^{2}$ ) patients was $233.83( \pm 69.39) \mathrm{dB} / \mathrm{m}$ (Table 4$)$. 


\section{Cureus}

\begin{tabular}{|c|c|c|}
\hline Characteristics & Categories & Frequency (Percentage) \\
\hline \multirow{3}{*}{ USG grading of fatty liver } & 1 & $50(39.4 \%)$ \\
\hline & 2 & $52(40.9 \%)$ \\
\hline & 3 & 25 (19.7\%) \\
\hline \multirow{4}{*}{ Steatosis grad } & so & $26(20.5 \%)$ \\
\hline & $\mathrm{s} 1$ & $22(17.3 \%)$ \\
\hline & s2 & $34(26.8 \%)$ \\
\hline & s3 & $45(35.4 \%)$ \\
\hline CAP (Mean \pm SD $\{$ Min, Max $\})$ & & $271.53 \pm 50.69(100,382) \mathrm{dB} / \mathrm{m}$ \\
\hline \multirow{5}{*}{ Fibrosis grading by LSM } & Fo & $76(59.8 \%)$ \\
\hline & $F_{1}$ & $35(27.6 \%)$ \\
\hline & F2 & $13(10.2 \%)$ \\
\hline & F3 & $3(2.4 \%)$ \\
\hline & $\mathrm{F} 4$ & $0(0 \%)$ \\
\hline LSM (Mean \pm SD \{Min, Max\}) & & $5.39 \pm 1.87(2.1,11.6) \mathrm{k!}$ \\
\hline
\end{tabular}

TABLE 3: Ultrasonography grading of fatty liver and FibroScan findings of the patients $(n=127)$

USG: ultrasonography, CAP: controlled attenuation parameter, LSM: liver stiffness measurement, SD: standard deviation

\begin{tabular}{|c|c|c|}
\hline Characteristics & Categories & CAP Values $(\mathrm{dB} / \mathrm{m})$ Mean $\pm \mathrm{SD}(\mathrm{Min}, \mathrm{Max})$ \\
\hline \multirow{2}{*}{ Sex } & Male & $268.51 \pm 50.21(100,373)$ \\
\hline & Female & $277.85 \pm 51.73(128,382)$ \\
\hline \multirow{2}{*}{ BMI } & $<23 \mathrm{~kg} / \mathrm{m}^{2}$ & $233.83 \pm 69.39(135,303)$ \\
\hline & $\geq 23 \mathrm{~kg} / \mathrm{m}^{2}$ & $273.4 \pm 49.22(100,382)$ \\
\hline \multirow{4}{*}{ Steatosis grade } & so & $199 \pm 36.6(100,235)$ \\
\hline & s1 & $248.55 \pm 6.17(239,258)$ \\
\hline & s2 & $275.47 \pm 9.31(260,289)$ \\
\hline & s3 & $321.69 \pm 23.56(291,382)$ \\
\hline Total & & $271.53 \pm 50.69(100,382)$ \\
\hline
\end{tabular}

TABLE 4: Mean CAP values according to sex, BMI, and steatosis grade $(n=127)$

BMI: body mass index, CAP: controlled attenuation parameter

Table 5 shows Pearson's correlation coefficient and the p-value for each of those correlations which depict that the total cholesterol level, TG, and BMI were positively correlated with CAP value, and the correlation was statistically significant $(\mathrm{p}<0.05)$. Similarly, SBP was found to be negatively correlated with statistically significant p-value. Other variables such as LDL cholesterol, HDL cholesterol, and FBG were positively correlated while age, DBP, WC, and ALT levels were found to be negatively correlated with CAP value; however, those were not statistically significant. 


\section{Cureus}

\begin{tabular}{|l|l|l|}
\hline Covariates & Pearson Correlation & P-value \\
\hline Age & -0.037 & 0.680 \\
\hline Total cholesterol & 0.234 & 0.008 \\
\hline LDL cholesterol & 0.140 & 0.115 \\
\hline HDL cholesterol & 0.022 & 0.008 \\
\hline TG & 0.227 & 0.010 \\
\hline SBP & -0.192 & 0.031 \\
\hline DBP & -0.107 & 0.231 \\
\hline BMI & 0.275 & 0.002 \\
\hline WC & -0.046 & 0.004 \\
\hline FBG & 0.070 & 0.432 \\
\hline ALT & -0.007 & 0.940 \\
\hline
\end{tabular}

\section{TABLE 5: Correlation of CAP values of FibroScan with other co-variates $(n=127)$}

CAP: controlled attenuation parameter, LDL: low-density lipoprotein, HDL: high-density lipoprotein, TG: triglyceride, SBP: systolic blood pressure, DBP: diastolic blood pressure, BMI: body mass index, WC: waist circumference, FBG: fasting blood glucose, ALT: alanine aminotransferase

On Spearman rank correlation, CAP steatosis grading was correlated positively and significantly with both the USG grading of fatty liver $(\mathrm{p}<0.001)$ and fibrosis grading by LSM $(\mathrm{p}=0.004)$ (Table 6 ).

\begin{tabular}{|l|l|l|}
\hline Grading & Spearman rank correlation & P-value \\
\hline USG grading of fatty liver & 0.623 & $<0.001$ \\
\hline Fibrosis grading by LSM & 0.252 & 0.004 \\
\hline
\end{tabular}

\section{TABLE 6: Correlation of CAP steatosis grading with USG grading and fibrosis grading}

CAP: controlled attenuation parameter, USG: ultrasonography, LSM: liver stiffness measurement

When univariate logistic regression was applied to calculate the odds ratio and its $95 \% \mathrm{CI}$ for each of the independent variables, those with BMI of $\geqslant 25 \mathrm{~kg} / \mathrm{m}^{2}$ were 3.66 times (95\% CI 1.01, 13.26) likely to have CAP $\geqslant 291 \mathrm{~dB} / \mathrm{m}$ (S3) than those with BMI $<25 \mathrm{~kg} / \mathrm{m}^{2}$, and it was statistically significant. Similarly, those with higher TG values were 2.12 times likely to have $\mathrm{CAP} \geqslant 291 \mathrm{~dB} / \mathrm{m}$ than those with lower TG values. There were increased odds of having $C A P \geqslant 291 \mathrm{~dB} / \mathrm{m}$ among females, those aged $<40$ years, diabetic, those with elevated WC and ALT >40 IU/L (Table 7). 


\section{Cureus}

\begin{tabular}{|c|c|c|c|c|}
\hline Characteristics & OR $(95 \% \mathrm{Cl})$ & $\mathrm{p}$-value & AOR $(95 \% \mathrm{Cl})$ & P-value \\
\hline Sex (male) & $0.80(0.37,1.72)$ & 0.559 & - & - \\
\hline Age $<40$ years & $1.70(0.57,5.05)$ & 0.337 & - & - \\
\hline Diabetes & $1.06(0.50,2.28)$ & 0.873 & - & - \\
\hline Hypertension & $0.87(0.42,1.80)$ & 0.702 & - & - \\
\hline Low HDL (<40 mg/dL in males, $<50 \mathrm{mg} / \mathrm{dL}$ in females) & $0.99(0.48,2.06)$ & 0.991 & - & - \\
\hline High TG ( $\geq 150 \mathrm{mg} / \mathrm{dL}$ ) & $2.12(0.83,5.41)$ & 0.118 & $2.14(0.83,5.54)$ & 0.118 \\
\hline Elevated $W C$ ( $\geq 90 \mathrm{~cm}$ in males, $\geq 80 \mathrm{~cm}$ in females) & $1.67(0.17,16.55)$ & 0.661 & - & - \\
\hline $\mathrm{BMI} \geq 25 \mathrm{~kg} / \mathrm{m}^{2}$ & $3.66(1.01,13.26)$ & 0.048 & $3.70(1.01,13.50)$ & 0.048 \\
\hline ALT $>40 \mathrm{IU} / \mathrm{L}$ & $1.03(0.47,2.25)$ & 0.945 & - & - \\
\hline
\end{tabular}

TABLE 7: Factors associated with severe steatosis by univariate and multivariate logistic regression

HDL: high-density lipoprotein, TG: triglyceride, WC: waist circumference, BMI: body mass index, ALT: alanine aminotransferase, AOR: adjusted odds ratio

The two variables high TG and BMI were taken to multivariate analysis. BMI $\geqslant 25 \mathrm{~kg} / \mathrm{m}^{2}$ was still statistically significant in multivariate analysis with adjusted OR of 3.70 (95\% CI 1.01, 13.50) with p-value of 0.048 implying that those with BMI $\geqslant 25 \mathrm{~kg} / \mathrm{m}^{2}$ were 3.7 times more likely to have higher CAP values ( $\geqslant 291 \mathrm{~dB} / \mathrm{m}$ ) than those with BMI $<25 \mathrm{~kg} / \mathrm{m}^{2}$.

The mean $\left( \pm\right.$ SD) value of CAP was $276.19( \pm 49.93) \mathrm{dB} / \mathrm{m}$ for those with BMI $\geqslant 25 \mathrm{~kg} / \mathrm{m}^{2}$, and it was 246.60 $( \pm 48.50) \mathrm{dB} / \mathrm{m}$ for those with BMI $<25 \mathrm{~kg} / \mathrm{m}^{2}$, and the difference was statistically significant ( $\mathrm{p}=0.016$, using independent t-test) (Figure 1). 


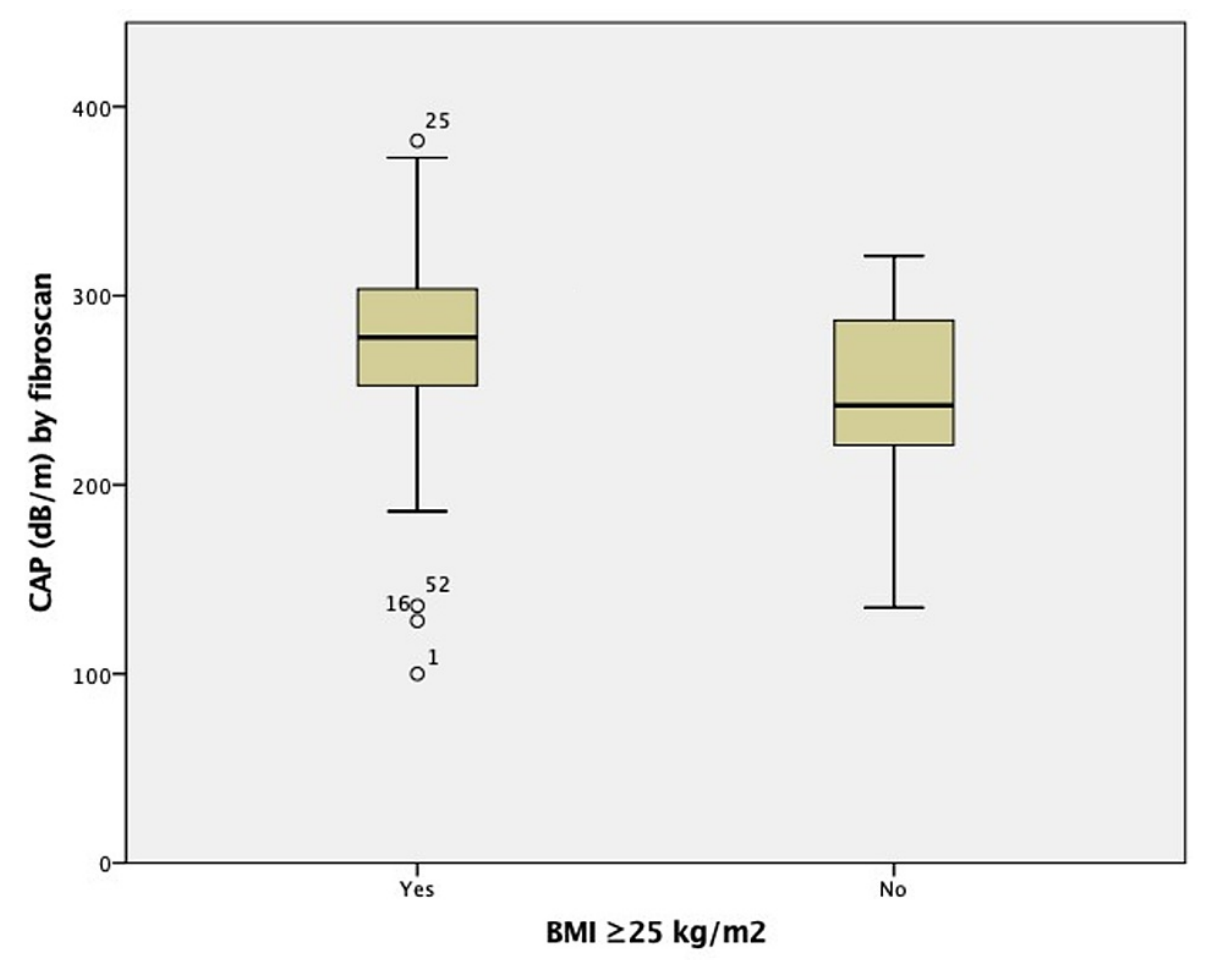

FIGURE 1: Comparison of CAP values among those with BMI $\geq 25 \mathrm{~kg} / \mathrm{m} 2$ and with $<25 \mathrm{~kg} / \mathrm{m} 2$

CAP: controlled attenuation parameter, BMI: body mass index

\section{Discussion}

Nonalcoholic fatty liver disease represents a major public health challenge. It is associated with type 2 diabetes, MetS, and other cardiovascular risk factors, and may lead to fibrosis, cirrhosis, liver cancer, liver failure requiring liver transplant, and mortality [7-11].

Controlled attenuation parameter is reported to be highly sensitive in detecting low-grade steatosis as fat deposition $\geqslant 10 \%$, and its values correlated well with the amount of steatosis assessed by LB in previous studies from different countries [3,12,13-16]. CAP can be performed simultaneously to LSM and in the same liver volume, making possible the simultaneous evaluation of both fibrosis and steatosis and thus consequently enhancing the spectrum of noninvasive methods for the exploration and follow-up of patients with chronic liver disease. In comparison with other modalities, CAP presents the advantage of being nonionizing, inexpensive, and nonsubject to the operator interpretation.

The mean $( \pm$ SD) CAP value of 127 NAFLD patients enrolled in this study was $271.53( \pm 50.69) \mathrm{dB} / \mathrm{m}$ which corresponds to S2 steatosis. Paul et al. also reported the mean CAP value of $278.57( \pm 49.13) \mathrm{dB} / \mathrm{m}$ in NAFLD patients during the first consultation [17]. Interestingly, 26 (20.5\%) patients diagnosed to have NAFLD by USG were unable to be diagnosed with fatty liver in accordance with the standard of CAP value by FibroScan. This could be due to the presence of hepatic fibrosis causing increased echogenicity of the liver on USG images, leading to a misdiagnosis of fatty liver. Also, because the mean BMI of patients in this study was $28.41 \mathrm{~kg} / \mathrm{m}^{2}$ and since for severely obese individuals, the sensitivity and specificity of USG in detecting NAFLD falls to $49 \%$ and $75 \%$, respectively, possibly due to image blurring caused by thickening of the abdominal subcutaneous and visceral fat, patients might be misdiagnosed as having fatty liver in USG [18].

However, liver USG is an accurate, reliable tool to detect moderate to severe fatty liver, with sensitivity and specificity of $84.8 \%$ and $93.6 \%$, respectively [19]. Also, the CAP value significantly correlates with the USGbased steatosis grading and the median CAP value for each USG-based steatosis grade shows a positive doseresponse relationship [20]. This observation is in line with our study also, which showed CAP steatosis grading correlated positively and significantly with the USG grading of fatty liver $(\mathrm{p}<0.001)$.

However, the CAP value is susceptible to interference by liver fibrosis in NAFLD [21]. This study also showed that CAP steatosis grading correlated positively and significantly with fibrosis grading $(\mathrm{p}=0.004)$. A similar observation has also been reported by Sehgal et al. [22]. To note is that $40.2 \%$ of patients in the current study had some degree of fibrosis, measured as LSM by FibroScan and 12.6\% had significant fibrosis (F2-F4); 
findings similar to the other study [23].

CAP values are associated with metabolic disorders [24]. Our study proved the same total cholesterol level, TG, and BMI correlated positively and significantly $(\mathrm{p}<0.05)$ with CAP value. These findings are also in line with Mansour et al. and Kwok et al. [23,25].

In our study, the mean $( \pm \mathrm{SD})$ value of CAP was $276.19( \pm 49.93) \mathrm{dB} / \mathrm{m}$ for those with $\mathrm{BMI} \geqslant 25 \mathrm{~kg} / \mathrm{m}^{2}$, and it was $246.60( \pm 48.50) \mathrm{dB} / \mathrm{m}$ for those with $\mathrm{BMI}<25 \mathrm{~kg} / \mathrm{m}^{2}$, and the difference was statistically significant ( $\mathrm{p}=0.016$ ). In addition, those with BMI $\geqslant 25 \mathrm{~kg} / \mathrm{m}^{2}$ had 3.7 times $(95 \%$ CI $1.01,13.50)$ more likely to have CAP $\geqslant 291 \mathrm{~dB} / \mathrm{m}$ (S3) than those with BMI $<25 \mathrm{~kg} / \mathrm{m}^{2}$ in multivariate analysis, and it was statistically significant. Shalimar et al. also showed BMI as an independent predictor of CAP even after adjusting for diabetes, serum TG, serum bilirubin, and age in a study done in India [26].

By non-Asian criteria $\left(\mathrm{BMI}<25 \mathrm{~kg} / \mathrm{m}^{2}\right.$ ), the current study constituted $15.7 \%$ lean NAFLD patients, which is comparable to the other study (11.5\%) [27]. While by Asian criteria (BMI $<23 \mathrm{~kg} / \mathrm{m}^{2}$ ), lean NAFLD constituted only $4.7 \%$ of total NAFLD patients which is lower than that reported in an Indian report (13.2\%) [28]. In the current study, the mean CAP $\left( \pm\right.$ SD) of lean NAFLD $\left(B M I<23 \mathrm{~kg} / \mathrm{m}^{2}\right)$ patients was $233.83( \pm 69.39) \mathrm{dB} / \mathrm{m}$.

The present study showed that SBP negatively and significantly correlated with CAP value. This finding is in contrast to the common dictum that CAP value, which is an indicator of steatosis, increases with the increase in the number of MetS components including HTN [29,30]. This disparity could be explained by the fact that most of the patients enrolled in this study were referred from general physicians for evaluation of fatty liver and were already getting treatment for comorbid conditions including HTN, and since more than half of the enrolled patients (51.2\%) in this study were hypertensive and under medications, this could have generated a contradicting inference of correlation between NAFLD and blood pressure.

\section{Conclusions}

The mean CAP value of NAFLD patients enrolled in this study was $271.53( \pm 50.69) \mathrm{dB} / \mathrm{m}$ that corresponds to moderate steatosis. However, obese NAFLD patients with $B M I \geqslant 25 \mathrm{~kg} / \mathrm{m}^{2}$ were 3.7 times likely to have severe steatosis than non-obese NAFLD patients with BMI $<25 \mathrm{~kg} / \mathrm{m}^{2}$.

In this study, CAP steatosis grading correlated positively and significantly with the USG grading of fatty liver and fibrosis grading by LSM. So, liver fat estimation in NAFLD patients can be done reliably with USG.

\section{Additional Information \\ Disclosures}

Human subjects: Consent was obtained or waived by all participants in this study. Institutional Review Board of National Academy of Medical Sciences, Bir Hospital issued approval 529/2077/78. Approval of the research study was accepted as exempt because the collection or study of existing data, documents, records, pathological specimens, or diagnostic specimens were recorded by the investigator in such a manner that subjects cannot be identified, directly or through identifiers linked to the subjects. Animal subjects: All authors have confirmed that this study did not involve animal subjects or tissue. Conflicts of interest: In compliance with the ICMJE uniform disclosure form, all authors declare the following: Payment/services info: All authors have declared that no financial support was received from any organization for the submitted work. Financial relationships: All authors have declared that they have no financial relationships at present or within the previous three years with any organizations that might have an interest in the submitted work. Other relationships: All authors have declared that there are no other relationships or activities that could appear to have influenced the submitted work.

\section{References}

1. Korenblat KM, Fabbrini E, Mohammed BS, Klein S: Liver, muscle, and adipose tissue insulin action is directly related to intrahepatic triglyceride content in obese subjects. Gastroenterology. 2008, 134:1369-75. 10.1053/j.gastro.2008.01.075

2. Lambert JE, Ramos-Roman MA, Browning JD, Parks EJ: Increased de novo lipogenesis is a distinct characteristic of individuals with nonalcoholic fatty liver disease. Gastroenterology. 2014, 146:726-35. 10.1053/j.gastro.2013.11.049

3. Stern C, Castera L: Non-invasive diagnosis of hepatic steatosis. Hepatol Int. 2017, 11:70-8. 10.1007/s12072016-9772-z

4. Grundy SM, Cleeman JI, Daniels SR, et al.: Diagnosis and management of the metabolic syndrome: an American Heart Association/National Heart, Lung, and Blood Institute scientific statement. Circulation. 2005, 112:2735-52. 10.1161/CIRCULATIONAHA.105.169404

5. Gaia S, Carenzi S, Barilli AL, et al.: Reliability of transient elastography for the detection of fibrosis in nonalcoholic fatty liver disease and chronic viral hepatitis. J Hepatol. 2011, 54:64-71.

10.1016/j.jhep.2010.06.022 
6. Kamali L, Adibi A, Ebrahimian S, Jafari F, Sharifi M: Diagnostic performance of ultrasonography in detecting fatty liver disease in comparison with Fibroscan in people suspected of fatty liver. Adv Biomed Res. 2019, 8:69. 10.4103/abr.abr_114_19

7. Harrison SA, Torgerson S, Hayashi PH: The natural history of nonalcoholic fatty liver disease: a clinical histopathological study. Am J Gastroenterol. 2003, 98:2042-7.

8. Bugianesi E, Leone N, Vanni E, et al.: Expanding the natural history of nonalcoholic steatohepatitis: from cryptogenic cirrhosis to hepatocellular carcinoma. Gastroenterology. 2002, 123:134-40. 10.1053/gast.2002.34168

9. Charlton M: Cirrhosis and liver failure in nonalcoholic fatty liver disease: molehill or mountain? . Hepatology. 2008, 47:1431-3. 10.1002/hep.22246

10. Marchesini G, Brizi M, Bianchi G, et al.: Nonalcoholic fatty liver disease: a feature of the metabolic syndrome. Diabetes. 2001, 50:1844-50. 10.2337/diabetes.50.8.1844

11. Targher G, Day CP, Bonora E: Risk of cardiovascular disease in patients with nonalcoholic fatty liver disease. N Engl J Med. 2010, 363:1341-50. 10.1056/NEJMra0912063

12. Sasso M, Miette V, Sandrin L, Beaugrand M: The controlled attenuation parameter (CAP): a novel tool for the non-invasive evaluation of steatosis using Fibroscan. Clin Res Hepatol Gastroenterol. 2012, 36:13-20. 10.1016/j.clinre.2011.08.001

13. Masaki K, Takaki S, Hyogo H, et al.: Utility of controlled attenuation parameter measurement for assessing liver steatosis in Japanese patients with chronic liver diseases. Hepatol Res. 2013, 43:1182-9. 10.1111/hepr.12094

14. Myers RP, Pollett A, Kirsch R, et al.: Controlled attenuation parameter (CAP): a noninvasive method for the detection of hepatic steatosis based on transient elastography. Liver Int. 2012, 32:902-10. 10.1111/j.14783231.2012.02781.x

15. Sasso M, Tengher-Barna I, Ziol M, et al.: Novel controlled attenuation parameter for noninvasive assessment of steatosis using Fibroscan ${ }^{\circledR}$ : validation in chronic hepatitis C. J Viral Hepat. 2012, 19:244-53. 10.1111/j.1365-2893.2011.01534.x

16. Chon YE, Jung KS, Kim SU, et al.: Controlled attenuation parameter (CAP) for detection of hepatic steatosis in patients with chronic liver diseases: a prospective study of a native Korean population. Liver Int. 2014, 34:102-9. 10.1111/liv.12282

17. Paul J, Venugopal RV, Peter L, Shetty KN, Shetti MP: Measurement of controlled attenuation parameter: a surrogate marker of hepatic steatosis in patients of nonalcoholic fatty liver disease on lifestyle modification - a prospective follow-up study. Arq Gastroenterol. 2018, 55:7-13. 10.1590/S0004-2803.201800000-07

18. Mottin CC, Moretto M, Padoin AV, Swarowsky AM, Toneto MG, Glock L, Repetto G: The role of ultrasound in the diagnosis of hepatic steatosis in morbidly obese patients. Obes Surg. 2004, 14:635-7. 10.1381/096089204323093408

19. Hernaez R, Lazo M, Bonekamp S, Kamel I, Brancati FL, Guallar E, Clark JM: Diagnostic accuracy and reliability of ultrasonography for the detection of fatty liver: a meta-analysis. Hepatology. 2011, 54:1082-90. 10.1002/hep.24452

20. Yoo JJ, Yoo YJ, Moon WR, et al.: Correlation of the grade of hepatic steatosis between controlled attenuation parameter and ultrasound in patients with fatty liver: a multi-center retrospective cohort study. Korean J Intern Med. 2020, 35:1346-53.

21. Fujimori N, Tanaka N, Shibata S, et al.: Controlled attenuation parameter is correlated with actual hepatic fat content in patients with non-alcoholic fatty liver disease with none-to-mild obesity and liver fibrosis. Hepatol Res. 2016, 46:1019-27. 10.1111/hepr.12649

22. Sehgal R, Mittal J, Singh I: Correlation of hepatic steatosis with hepatic fibrosis in NAFLD patients by Fibroscan. AJMR. 2020, 9:1-7. 10.47009/ajmr.2020.9.3.ME1

23. Mansour AM, Bayoumy EM, ElGhandour AM, El-Talkawy MD, Badr SM, Ahmed A: Assessment of hepatic fibrosis and steatosis by vibration-controlled transient elastography and controlled attenuation parameter versus non-invasive assessment scores in patients with non-alcoholic fatty liver disease. Egypt Liver J. 2020, 10:33. 10.1186/s43066-020-00044-W

24. Sun WL, Sun CG, Chen GY, Pan Q, Zeng J, Shan PP, Fan JG: A clinical study of the association between hepatic controlled attenuation parameter and metabolic syndrome. [Article in Chinese]. Zhonghua Gan Zang Bing Za Zhi. 2017, 25:128-33. 10.3760/cma.j.issn.1007-3418.2017.02.010

25. Kwok R, Choi KC, Wong GL, et al.: Screening diabetic patients for non-alcoholic fatty liver disease with controlled attenuation parameter and liver stiffness measurements: a prospective cohort study. Gut. 2016, 65:1359-68. 10.1136/gutjnl-2015-309265

26. Shalimar, Kumar R, Rout G, et al.: Body mass index-based controlled attenuation parameter cut-offs for assessment of hepatic steatosis in non-alcoholic fatty liver disease. Indian J Gastroenterol. 2020, 39:32-41. 10.1007/s12664-019-00991-2

27. Dela Cruz AC, Bugianesi E, George J, et al.: Characteristics and long-term prognosis of lean patients with nonalcoholic fatty liver disease. Gastroenterology. 2014, 146:909. 10.1016/S0016-5085(14)63307-2

28. Kumar R, Rastogi A, Sharma MK, Bhatia V, Garg H, Bihari C, Sarin SK: Clinicopathological characteristics and metabolic profiles of non-alcoholic fatty liver disease in Indian patients with normal body mass index: do they differ from obese or overweight non-alcoholic fatty liver disease?. Indian J Endocrinol Metab. 2013, 17:665-71. 10.4103/2230-8210.113758

29. de Lédinghen V, Vergniol J, Capdepont M, et al.: Controlled attenuation parameter (CAP) for the diagnosis of steatosis: a prospective study of 5323 examinations. J Hepatol. 2014, 60:1026-31. 10.1016/j.jhep.2013.12.018

30. Paudel MS, Tiwari A, Mandal A, Shrestha B, Kafle P, Chaulagai B, KC S: Metabolic syndrome in patients with non-alcoholic fatty liver disease: a community based cross-sectional study. Cureus. 2019, 11:e4099. 10.7759/cureus.4099 